\title{
Degree and Pattern of Gene Flow in Several Scleractinian Corals in the Ryukyu Archipelago, Southern Japan ${ }^{1}$
}

\author{
Akira Nishikawa
}

\begin{abstract}
Dispersal distance of planktonic larvae of coral reef organisms is influenced by their ecological characteristics and environmental factors such as current flow and physical structure of reefs. This study reviews the degree and pattern of genetic differentiation in scleractinian corals in the Ryukyu Archipelago, compared with other regions. Small-scale genetic heterogeneity, but broadscale homogeneity, was detected in some species, including brooders and spawners in the Ryukyus. Comparison with other regions indicated that limited gene flow on a small spatial scale (i.e., self-recruitment) seemed to occur in many regions. However, the degree of gene flow over larger distances was complex and species-dependent. With an implication for conservation in the Ryukyus, the larval source hypothesis, which states that coral larvae were recruited from the Kerama Islands to the Okinawa Islands, was consistent with results illustrating high gene flow in some species. Thus, conservation of corals in the Kerama Islands is high priority. Detection of genetic breaks between the southern and central Ryukyus was not common among species. The genetic structure observed in corals is highly variable and depends on both species and spatial scale in the Ryukyus. In addition, the complex genetic structures of corals may be related to coral-specific destructive events, such as bleaching, outbreaks of crown-of-thorns starfish, and disease. Further studies will provide new insights and a more detailed view of the genetic structure of corals by using different markers (e.g., microsatellites) and approaches (assignment tests and clustering analysis), which will provide useful information for coral reef conservation.
\end{abstract}

Connectivity among reefs is important in the conservation and management of coral reefs. The dispersal distance of planktonic larvae of coral reef organisms is influenced by ecological features of the larval species, such as reproductive modes and larval duration periods (Doherty et al. 1995, Ayre et al. 1997, Nishikawa et al. 2003), and by environmental factors, such as current flow (Ho-

${ }^{1}$ This study was supported by a grant from the 21 st Century Center of Excellence (COE) Program to the University of the Ryukyus. Manuscript accepted 26 August 2007.

${ }^{2}$ Sesoko Station, Tropical Biosphere Research Center, University of the Ryukyus, 3422 Sesoko, Motobu, Okinawa 905-0227, Japan (e-mail: akira_nishikawa27@ ybb.ne.jp).

Pacific Science (2008), vol. 62, no. 3:413-421

(C) 2008 by University of Hawai'i Press

All rights reserved henlohe 2004, Baums et al. 2006) and the physical structure of the reefs (e.g., shoreline or isolated archipelago). For example, some aspects of long-distance migrations can occur via a series of relatively short steps (e.g., between reef patches within a reef and between adjacent reefs) along a continental shoreline, such as the Great Barrier Reef in Australia, but it is difficult for such short-step dispersal patterns to occur in isolated island systems surrounded by oceans, such as Pacific reefs (e.g., Hawai'i, Marshall Islands, Society Islands).

The Ryukyu Archipelago has unique geographic, hydrodynamic, and historical features. The Ryukyu Archipelago is isolated, being located approximately $500 \mathrm{~km}$ from the Eurasian continent, and comprises many islands, which consists of short and long steps of island connections (from several kilometers to over $200 \mathrm{~km}$ apart) between Taiwan and the Japanese mainland (Figure 1). 


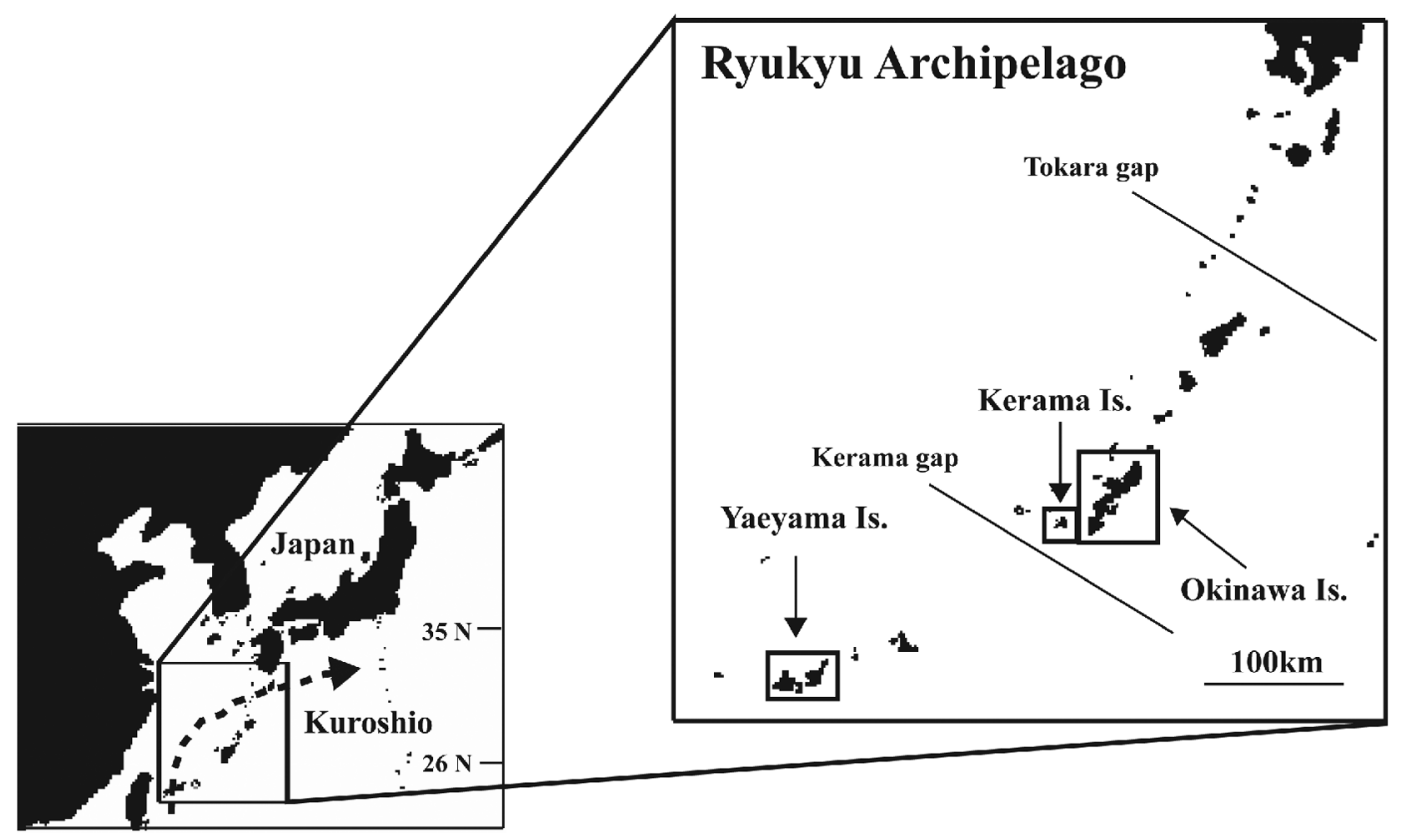

Figure 1. Map of the Ryukyu Archipelago. Dashed arrow shows direction of the Kuroshio Current.

In addition, a strong current, known as the Kuroshio, runs from the northern Philippines through the archipelago. The Ryukyu Archipelago also has a unique historical background attributable to past glacial periods. These features likely influenced genetic structures of both terrestrial and marine organisms.

Based on the clustered analysis of amphibian and reptilian species, the Ryukyus can be divided into three geographic groups, the southern, central, and northern Ryukyus, separated by the Kerama and Tokara gaps (Figure 1, reviewed in Ota 1998). In the case of marine invertebrates, the effects of the Kuroshio Current are considered because many marine organisms have high dispersal abilities through water currents. Phylogenetic and population genetic studies, however, have been limited in marine taxa. For example, in a few studies, high genetic homogeneity of the sea star Acanthaster planci has been reported in the Ryukyus, which may have been the result of a high exchange of individuals via the Kuroshio Current (Nishida and Lucas
1988). However, genetic divergence between the southern and central Ryukyus is apparent in tideland gastropod species Cerithidea cingulata (Kojima et al. 2006). Thus, population structures of marine animals are also complex in the Ryukyu Archipelago. Comparison of other marine taxa will provide further information on gene flow in these areas.

\section{GENE FLOW PATTERN OF CORALS}

Some studies have detected small, but significant, genetic differentiation over short distances (a few to $<100 \mathrm{~km}$ ) using allozyme electrophoresis in several coral species in the Ryukyu Archipelago (Adjeroud and Tsuchiya 1999, Yamamoto 2001, Kimmie 2003, Nishikawa and Sakai 2003, 2005a,b, Nishikawa et al. 2003). Significant genetic differences were detected in all four species within groups (Fsc) but were not detected in two of four species among groups (Fct) in comparisons between local and relatively longer distances (approximately $500 \mathrm{~km}$ ) in a previous study (Nishikawa and Sakai 2003, 2005b, 
TABLE 1

Genetic Differentiations within Groups (Fsc) and among Groups (Fct) Using $\theta$ (Weir and Cockerham 1984) by TFPGA (Miller 1997)

\begin{tabular}{lcccr}
\hline \hline Species & Fsc & $\mathrm{Nem}^{a}$ & Fct & Nem \\
\hline Acropora digitifera (spawner) & $0.024^{* *}$ & 10.2 & 0.011 & 22.5 \\
Acropora tenuis (spawner) & $0.066^{*}$ & 3.5 & 0.015 & 16.4 \\
Stylophora pistillata (brooder) & $0.215^{* *}$ & 0.9 & $0.142^{*}$ & 1.5 \\
Goniastrea aspera (spawner and brooder) & $0.087^{* *}$ & 2.6 & $0.039^{* *}$ & 6.2 \\
\hline
\end{tabular}

Note: Significant departures from $\theta=0$ were evaluated using 95 or $99 \%$ confidence intervals generated by bootstrapping over each locus. * $P<.05$; $^{* *}, P<.01$.

a Number of migration per generation.

Nishikawa et al. 2003) (Table 1). In addition, genetic differentiations were relatively lower among groups than within groups. The tendency for small-scale genetic heterogeneity, but broader-scale homogeneity, has been determined in these coral studies. The same pattern was also reported in a broad-scale study in the Great Barrier Reef (Ayre and Hughes 2000). They detected significant genetic differentiation on small spatial scales (a few kilometers) in all nine species (five brooders, four spawners) examined but not longer distances (up to 2,000 km) in five of nine species using allozyme markers. They suggested that most recruitment by corals was very local, but that enough propagules are widely dispersed to ensure vast, effective panmictic populations.

Significant genetic differentiation (or selfrecruitment) of corals on a local scale has also been reported in other regions using DNA markers (Baums et al. 2005, Maier et al. 2005, Underwood et al. 2007). Using five microsatellite markers and assignment tests, Baums et al. (2005) reported a high selfrecruitment rate in species of the spawner Acropora in some Caribbean localities. Using spatial autocorrelation analysis, Underwood et al. (2007) demonstrated that the brooder species Seriatopora hystrix in Western Australian populations was locally subdivided; moreover, although the majority of larval recruitment occurred within $100 \mathrm{~m}$ of their natal colony, the recruitment was supplemented by recent, but less frequent, input of larvae from outside the local area. Although historical and physical features are different in those regions, limited gene flow in corals on a local spatial scale seems to be a general feature.

Large-scale gene flow patterns, however, seem to be different across regions. For example, Baums et al. (2005 [Acropora palmata]) and Vollmer and Palumbi (2007 [A. cervicornis]) showed significant genetic population structures between the western and eastern regions of the Caribbean $(2,000 \mathrm{~km})$. This may have been the result of regional small eddies in the spawning season around Puerto Rico, the boundary area between the western and eastern populations in the Caribbean (Baums et al. 2006). Magalon et al. (2005) also detected genetic differentiation in isolated island systems between Tonga and French Polynesia at similar spatial scales $(2,000 \mathrm{~km})$. In contrast, Ayre and Hughes (2000) detected no clear genetic structure in some coral species over 2,000 km scales in the Great Barrier Reef (but see Smith-Keune and van Oppen 2006). Among four coral species in the Ryukyu Archipelago, genetic differentiation was detected between the southern and central Ryukyus in two of the species, but the other two showed no significant genetic differentiation (Figures 2, 3). Large-scale gene flow patterns in corals are complex and may be dependent on specific regional features, including historical and present physical factors such as currents.

Only a few reports have shown clear relationships of isolation by distance in corals (reviewed in van Oppen and Gates 2006). Although the examination of genetic isolation by distance has the potential to increase confidence in the biological significance of 


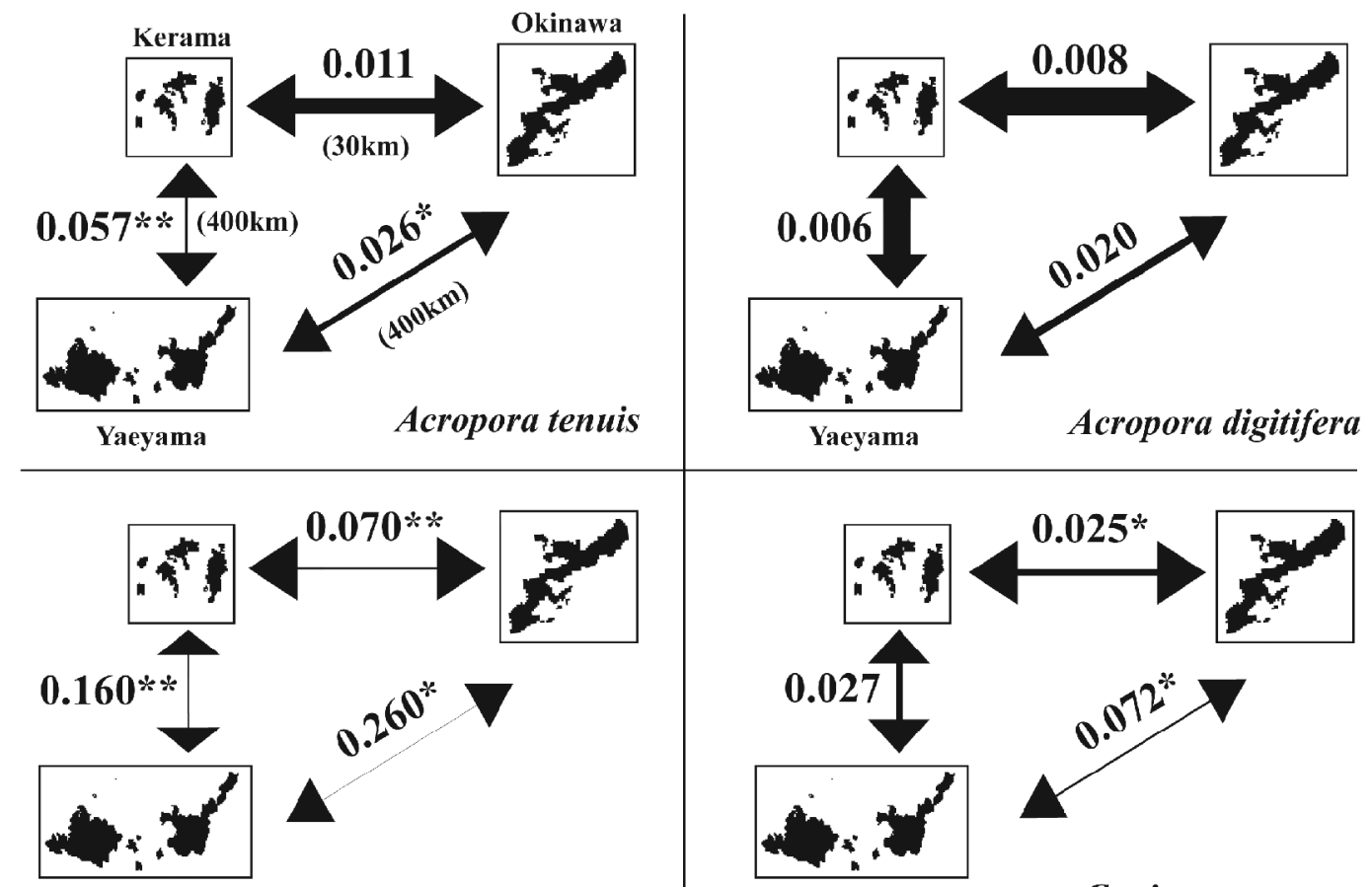

Stylophora pistillata

Goniastrea aspera

Figure 2. Genetic differentiation (Fst) among the populations of four species of corals (spawner: Acropora tenuis, $A$. digitifera; brooder: Stylophora pistillata; spawner and brooder: Goniastrea aspera). Significant departures from $\theta=0$ were evaluated using 95 or $99 \%$ confidence intervals generated by bootstrapping over each locus. The Okinawa, Kerama, and Yaeyama Islands correspond to boxes shown in Figure 1. Arrow thickness indicates degree of gene flow (calculated from Fst values). ${ }^{*}, P<.05$, ${ }^{* *}, P<.01$.

small Fst values (Palumbi 2003), no relationship between genetic differentiation (Fst) and geographic distance has been reported in any coral in the Ryukyu Archipelago (Adjeroud and Tsuchiya 1999, Kimmie 2003; Nishikawa unpubl. data). Hellberg (1994, 1995) conducted an allozyme study with the brooding temperate coral Balanophyllia elegans on the Pacific coast of North America. He found the expected slope for isolation by distance at medium spatial scales $(1-50 \mathrm{~km})$, but slopes at larger $(100-1,000 \mathrm{~km})$ distances were shallower than expected for a strict steppingstone model. The time required for the influence of migration to equilibrate with genetic drift is generally long (Hellberg 2007 and references therein); thus he suggested that ge- netic drift under low levels of gene flow took many generations to reflect these results. In addition, Johnson and Black (2006) suggested that complex hydrodynamics associated with island systems may have disrupted patterns of isolation by distance in the intertidal snail Austrocochlea constricta in Western Australia. Based on empirical data, detection of isolation by distance has only been reported in a few corals and found to be variable by region and species, leading to complex pairwise estimates of population subdivisions, especially in corals. In addition, complicated genetic structures of corals may be related to destructive events, such as bleaching, outbreaks of crown-of-thorns starfish, and disease. Thus, investigations of the relationship between 


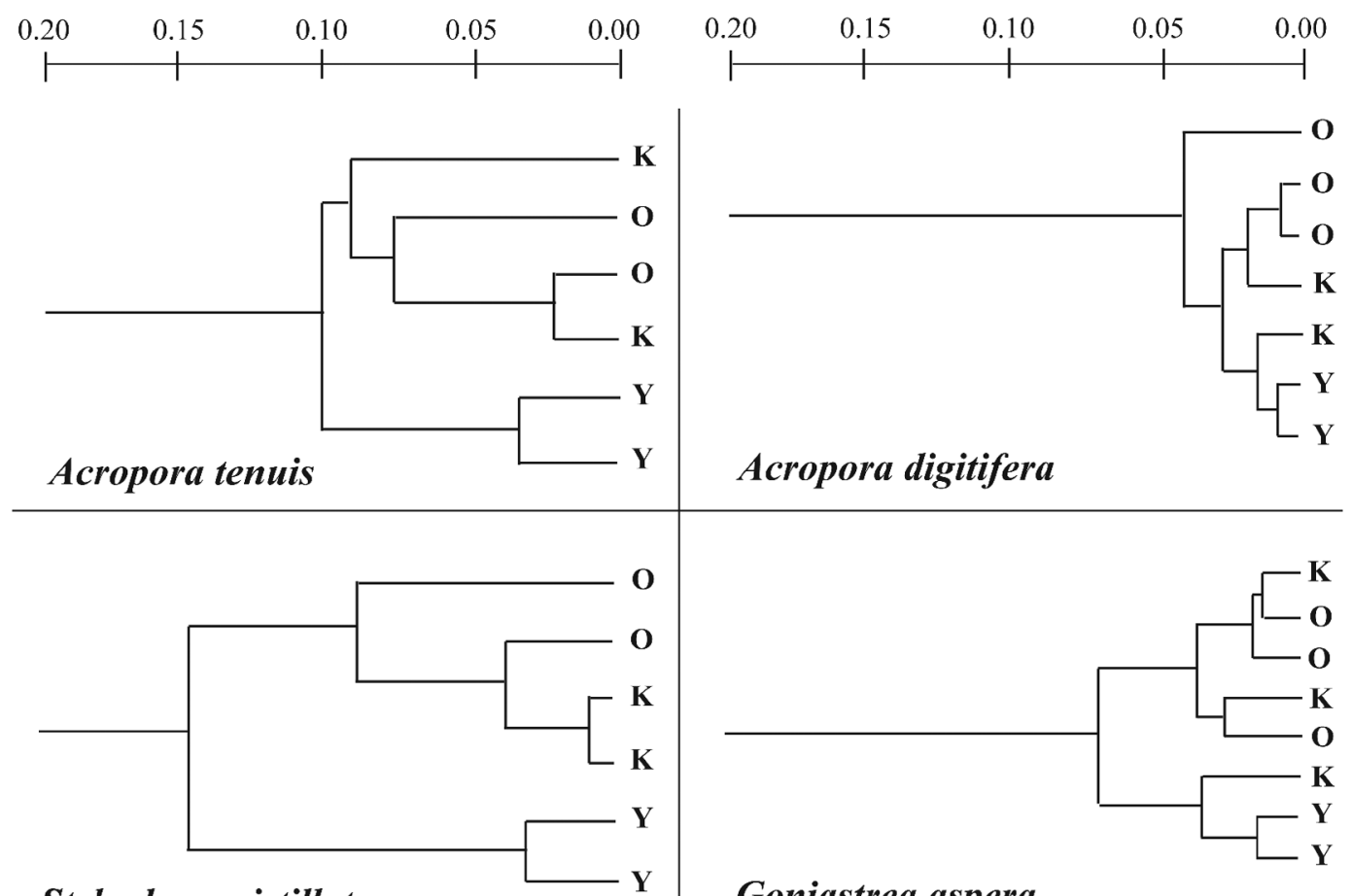

Stylophora pistillata

Goniastrea aspera

FIgURE 3. The UPGMA dendrogram showing relationships among populations of four species of corals based on Nei's unbiased genetic distance $D$.

the genetic structure and such destructive events should be informative in coral reef conservation.

\section{IMPLICATIONS FOR CORAL CONSERVATION}

\section{Status of Corals in the Ryukyu Archipelago}

The 1998 coral-bleaching event was the most extensive and severe recorded to date (Hoegh-Guldberg 1999, Goreau et al. 2000), and coral populations in the Okinawa Islands, particularly populations of branching species, declined severely (Loya et al. 2001). For example, at Sesoko Island, northwest of the Okinawa Islands, coral species richness was reduced by $61 \%$ and coral cover by $85 \%$. The populations of potential coral parental colonies (healthy and sexually mature) critically declined after bleaching at the natal area around the Okinawa Islands (especially for branching Acropora and Pocillopora). Thus, recovery of Okinawan coral populations was predicted to be difficult without larval supplies from other regions. In contrast, some reefs around the Kerama and Yaeyama regions, approximately 30 and $500 \mathrm{~km}$ from the Okinawa Islands, respectively, maintained relatively healthy coral populations on many reefs, even after mass coral bleaching (Taniguchi and Iwao 2000, Ministry of the Environment of Japan 2002). Thus, whether the Kerama and Yaeyama regions play key roles in larval recruitment is important in the discussion of coral reef conservation around the Okinawa Islands.

\section{Hydrodynamics around the Okinawa Islands}

Kimura et al. (1992) studied local current flow using drift cards and hypothesized that 
the Kerama Islands were a source of coral larva for the Okinawa Islands. Nadaoka et al. (2002) also supported this hypothesis by conducting oceanographical and biological studies that examined current direction and larval duration periods using high-frequency radar, global positioning system buoys, and larval experiments. They cultured the larvae of Acropora tenuis and A. nasuta under laboratory conditions to establish the planktonic period before their settlement after spawning. They demonstrated that the sea-surface current flowed from the Kerama Islands to the Okinawa Islands during the spawning period for Acropora spp. (full moon in June), and the time required for the buoys to reach the west coast of Okinawa from the Kerama Islands corresponded to the length of the period between spawning and the peak of planula settlement (4-5 days).

\section{Genetic Connectivity}

Rough pictures of genetic differentiation among the three regions (Yaeyama, Kerama, and Okinawa) are shown using the available allozyme data on the spawning species $A$. tenuis and A. digitifera, the brooding Stylophora pistillata, and the spawning and brooding Goniastrea aspera in the Ryukyu Archipelago (Figure 2). Genetic differentiation (Fst) between the Okinawa $(\mathrm{O})$ and Kerama $(\mathrm{K})$ regions (30 to $150 \mathrm{~km}$ apart; Fst $=0.008$ to 0.070 ) was lower than that between the Okinawa and Yaeyama $(\mathrm{Y})$ regions (up to $500 \mathrm{~km}$ apart; Fst $=0.020$ to 0.260$)$ in all species. Dendrograms based on Nei's (1978) genetic distance also indicated that population $\mathrm{Y}$ is isolated from the $\mathrm{K}$ and $\mathrm{O}$ regions in two of four species (Figure 3). As described earlier, current flow (Nadaoka et al. 2002) and geographical proximity suggest that coral populations in the Kerama Islands are a major source of coral planulae needed for the recovery of both brooding and spawning coral communities around the Okinawa Islands, which is also supported by genetic data.

The genetic break between the southern and central Ryukyus is not a common feature in corals. There is no island between the southern and central Ryukyus (200 km), but whether this geographic distance acts as a barrier (or filter) for transport of coral larvae is still unclear. If barriers (assumed here to be geographic distance) that isolate populations of several species exist, they can be identified by comparing the genealogies of sympatric taxa (Hellberg 2007). Populations of the southern Ryukyus were assigned to different clusters from those of the central Ryukyus based on Nei's (1978) genetic distance in three species (A. tenuis, S. pistillata [Figure 3], and Pocillopora damicornis [Adjeroud and Tsuchiya 1999]), but not in three other species (A. digitifera, G. aspera [Figure 3], and Seriatopora hystrix [Kimmie 2003]). These results suggest that the barrier, if there is one, is not sufficient to restrict gene flow between the areas.

The two gaps, Tokara Gap and Kerama Gap (Figure 1), appear to be important factors in the formation of genetic structures of other marine organisms. Kojima et al. (2003, 2006) conducted phylogeographic analysis of intertidal gastropods using the mitochondrial COI gene. The tideland snail Batillaria multiformis and its sister species B. flectosiphonata were suggested to have diverged into two genetically independent lineages through an isolation by the Tokara Gap (Kojima et al. 2003). Populations of B. flectosiphonata and tideland snail Cerithidea singulata were also shown to have differentiated genetically on both sides of the Kerama Gap (Kojima et al. 2003, 2006). These results indicate that historical events related to glacial sea level changes played important roles in the past dispersal of other marine organisms. Phylogeographic studies using mtDNA markers of corals are limited due to their slow mutation rate (Shearer et al. 2002). On the other hand, some nuclear intron DNA markers are now available (Mini-collagen: Wang et al. 1995; B-tubulin: Lopez and Knowlton 1997; Cnox2: Hayward et al. 2001; PaxC: Oppen et al. 2001; Calmodulin: Vollmer and Palumbi 2002), although these markers have been used mainly for studies of the phylogeny of corals as related to hybridization (Hatta et al. 1999, Oppen et al. 2001, 
Vollmer and Palumbi 2002). If some analyses (e.g., Nested Clade Analysis [Templeton 1998]) are applied using these nuclear markers, further information about the historic effect of the Kerama Gap on coral larval dispersal will be provided.

For coral conservation, it is often important to know the ecological timescales of larval connectivity among reefs. Genetic approaches using allozymes focus on evolutionary timescales because of the low variability of the markers. However, the assignment method, using highly polymorphic markers, makes possible the examination of larval recruitment on ecological timescales. For example, in the Okinawa Islands, assignment tests could be used to test the hypothesis that after the 1998 coral-bleaching event, the recolonizing juvenile colonies largely originated from other regions and dispersed to the Okinawa Islands. Thus, more data on shorter timescales should be obtained for these areas. Microsatellite analyses of a few species are also under way in the Ryukyus. Thus new insights using more-sensitive markers will be reported in the near future to provide a blueprint of coral genetic structure, which will be useful for coral reef conservation.

\section{ACKNOWLEDGMENTS}

I am grateful to Akira Iguchi and two anonymous reviewers for comments on the manuscript.

\section{Literature Cited}

Adjeroud, M., and M. Tsuchiya. 1999. Genetic variation and clonal structure in the scleractinian coral Pocillopora damicornis in the Ryukyu Archipelago, southern Japan. Mar. Biol. (Berl.) 134:753-760.

Ayre, D. J., A. R. Davis, T. Llorens, and M. Billingham. 1997. Genetic evidence for contrasting patterns of dispersal in solitary and colonial ascidians. Mar. Biol. (Berl.) 130:51-62.

Ayre, D. J., and T. P. Hughes. 2000. Genotypic diversity and gene flow in brooding and spawning corals along the Great Bar- rier Reef, Australia. Evolution 54:15901605.

Baums, I. B., M. W. Miller, and M. E. Hellberg. 2005. Regionally isolated populations of an imperiled Caribbean coral, Acropora palmata. Mol. Ecol. 14:13771390.

Baums, I. B., C. B. Paris, and L. M. Cherubin. 2006. A bio-oceanographic filter to larval dispersal in a reef-building coral. Limnol. Oceanogr. 51:1969-1981.

Doherty, P. J., S. Planes, and P. Mather. 1995. Gene flow and larval duration in seven species of fish from the Great Barrier Reef. Ecology 76:2373-2391.

Goreau, T. J., T. R. McClanahan, R. L. Hayes, and A. Strong. 2000. Conservation of coral reefs after the 1998 global bleaching event. Conserv. Biol. 14:5-15.

Hatta, M., H. Fukami, W. Wang, M. Omori, K. Shimoike, T. Hayashibara, Y. Ina, and T. Sugiyama. 1999. Reproductive and genetic evidence for a reticulate evolutionary history of mass-spawning corals. Mol. Biol. Evol. 16:1607-1613.

Hayward, D. C., J. Catmull, J. S. ReeceHoyce, H. Berghammer, H. Dodd, S. J. Hann, D. J. Miller, and E. E. Ball. 2001. Gene structure and larval expression of cnox-2Am from the coral Acropora millepora. Dev. Genes Evol. 211:10-19.

Hellberg, M. E. 1994. Relationship between inferred levels of gene flow and geographic distance in a philopatric coral, Balanophyllia elegans. Evolution 48:1829-1854.

- 1995. Stepping stone gene flow in solitary coral Balanophyllia elegansequilibrium and non equilibrium at different spatial scales. Mar. Biol. (Berl.) 123:573-581.

123.573 2007. Footprints on water: The genetic wake of dispersal among reefs. Coral Reefs 26:463-473.

Hoegh-Guldberg, O. 1999. Coral bleaching, climate change, and the future of the world's coral reefs. Mar. Freshwater Res. 50:839-866.

Hohenlohe, P. A. 2004. Limits to gene flow in marine animals with planktonic larvae: Models of Littorina species around Point 
Conception, California. Biol. J. Linn. Soc. 82:169-187.

Johnson, M. S., and R. Black. 2006. Islands increase genetic subdivision and disrupt patterns of connectivity of intertidal snail in a complex archipelago. Evolution 60:2498-2506.

Kimmie, W. W. H. 2003. Genetic differentiation of the scleractinian coral Seriatopora bystrix populations in the Ryukyu Archipelago. M.S. thesis, University of the Ryukyus, Okinawa, Japan.

Kimura, T., T. Hayashibara, and K. Shimoike. 1992. Dispersal of coral larvae from the Kerama Islands: A report of drift card experiments. Midoriishi 3:18-21 [in Japanese].

Kojima, S., S. Kamimura, A. Iijima, T. Kimura, T. Kurozumi, and T. Furota. 2006. Molecular phylogeny and population structure of tideland snails in the genus Cerithidea around Japan. Mar. Biol. (Berl.) 149:525-535.

Kojima, S., S. Kamimura, T. Kimura, I. Hayashi, A. Iijima, and T. Furota. 2003. Phylogenetic relationships between the tideland snails Batillaria flectosiphonata in the Ryukyu Islands and $B$. multiformis in the Japanese Islands. Zool. Sci. (Tokyo) 20:1423-1433.

Lopez, J. V., and N. Knowlton. 1997. Discrimination of species in the Montastrea annularis complex using multiple genetic loci. Proc. 8th Int. Coral Reef Symp. 2:1613-1618.

Loya, Y., K. Sakai, K. Yamazato, Y. Nakano, H. Sambali, and R. Van Woesik. 2001. Coral bleaching: The winners and losers. Ecol. Lett. 4:122-131.

Magalon, H., M. Adjeroud, and M. Veuille. 2005. Patterns of genetic variation do not correlate with geographical distance in the reefbuilding coral Pocillopora meandrina in the South Pacific. Mol. Ecol. 14:18611868.

Maier, E., R. Tollrian, B. Rinkevich, and B. Nurnberger. 2005. Isolation by distance in the scleractinian coral Seriatopora bystrix from the Red Sea. Mar. Biol. (Berl.) 147:1109-1120.
Ministry of the Environment of Japan. 2002. Report of the International Coral Reef Research and Monitoring Center. Pages 13-34. International Coral Reef Research and Monitoring Center, Ishigaki [in Japanese].

Nadaoka, K., S. Harii, J. Mitsui, H. Tamura, G. Hanada, E. Paringit, Y. Nihei, S. Fujii, K. Sato, T. Matsuoka, S. Kakuma, T. Ikema, K. Iwao, and T. Takahashi. 2002. Larval tracking using small drifters and larval settlement experiments to examine long-distance larval transport of corals. Proc. Coastal Eng., JSCE 49:366-370 [in Japanese].

Nei, M. 1978. Estimation of average heterozygosity and genetic distance from a small number of individuals. Genetics 89:583190.

Nishida, M., and J. S. Lucas. 1988. Genetic differences between geographic populations of the crown-of-thorns starfish throughout the Pacific Region. Mar. Biol. (Berl.) 98:359-368.

Nishikawa, A., M. Katoh, and K. Sakai. 2003. Larval settlement rates and gene flow of broadcast-spawning (Acropora tenuis) and planula-brooding (Stylophora pistillata) corals (Scleractinia). Mar. Ecol. Prog. Ser. 256:87-97.

Nishikawa, A., and K. Sakai. 2003. Genetic variation and gene flow of broadcast spawning and planula brooding coral, Goniastrea aspera (Scleractinia), in the Ryukyu Archipelago, southern Japan. Zool. Sci. (Tokyo) 20:1031-1038.

_ 2005a. Gene flow of scleractinian coral Goniastrea aspera around the Okinawa Islands. Coral Reefs 24:318-323.

- 2005b. Settlement competencyperiods of planula and genetic differentiation of the scleractinian coral Acropora digitifera. Zool. Sci. (Tokyo) 4:391-399.

Ota, H. 1998. Geographic patterns of endemism and speciation in amphibians and reptiles of the Ryukyu Archipelago, Japan, with special reference to their paleogeographical implications. Res. Popul. Ecol. 40:189-204.

Palumbi, S. R. 2003. Population genetics, de- 
mographic connectivity, and the design of marine reserves. Ecol. Appl. 13:S146S158.

Shearer, T. L., M. J. H. van Oppen, S. L. Romano, and G. Worheide. 2002. Slow mitochondrial DNA sequence evolution in the Anthozoa (Cnidaria). Mol. Ecol. 11:24752487.

Smith-Keune, C., and M. J. H. van Oppen. 2006. Genetic structure of a reef-building coral from thermal distinct environments on the Great Barrier Reef. Coral Reefs 25:493-502.

Taniguchi, H., and K. Iwao. 2000. Change of coral number and density in Aka Island. Rep. Akajima Mar. Sci. Lab. 11:22-23 [in Japanese].

Templeton, A. R. 1998. Nested Clade Analyses of phylogeographic data: Testing hypotheses about gene flow and population history. Mol. Ecol. 7:381-397.

Underwood, J. N., L. D. Smith, M. J. H. van Oppen, and J. P. Gilmour. 2007. Multiple scales of genetic connectivity in a brooding coral on isolated reefs following catastrophic bleaching. Mol. Ecol. 16:771-784.

van Oppen, M. J. H., and R. D. Gates. 2006. Conservation genetics and the resilience of reef-building corals. Mol. Ecol. 15:38633883 . van Oppen, M. J. H., B. J. McDonald, B. Willis, and D. J. Miller. 2001. The evolutionary history of the coral genus Acropora (Scleractinia, Cnidaria) based on a mitochondrial and a nuclear marker: Reticulation, incomplete lineage sorting, or morphological convergence? Mol. Biol. Evol. 18:1315-1329.

Vollmer, S. V., and S. R. Palumbi. 2002. Hybridization and the evolution of reef coral diversity. Science (Washington, D.C.) 296:2023-2025.

- 2007. Restricted gene flow in the Caribbean staghorn coral Acropora cervicornis: Implications for the recovery of endangered reefs. J. Hered. 98:40-50.

Wang, W., M. Omori, T. Hayashibara, K. Shimoike, M. Hatta, T. Sugiyama, and T. Fujisawa. 1995. Isolation and characterization of a mini-collagen gene encoding a nematocyst capsule protein from a reef-building coral, Acropora donei. Gene 152:195-200.

Yamamoto, T. 2001. Genetic population structures of two massive corals (Goniastrea aspera and Favites chinensis) with different reproductive modes around Okinawa. M.S. thesis, University of the Ryukyus, Okinawa, Japan [in Japanese]. 
